\title{
Integrating phase change materials into concrete through microencapsulation using
} cenospheres

\author{
Fengjuan Liu, Jialai Wang*, Xin Qian \\ Department of Civil, Construction and Environmental Engineering, The University of Alabama, \\ Tuscaloosa, AL 35487, United States
}

\section{ABSTRACT}

7

Phase change materials (PCMs) can enhance the building energy efficiency through Thermal Energy Storage and thermal regulation. Microencapsulated PCMs (MEPCMs) provide a better utilization of PCMs with building materials. This study proposes a novel method to encapsulate PCMs into cenospheres which are hollow fly ash particles generated in coal burning power plants with size ranging from a few micrometers to hundreds of micrometers. The shell of the cenosphere inherently has some small pores which are sealed by a thin layer of glass-crystalline film. By removing this film through chemical etching, these holes can be exposed, providing paths for PCMs moving into the internal void of cenospheres. A thin layer of silica is coated on the PCM loaded cenospheres to prevent the possible leakage of liquid PCMs. The produced PCM microcapsules are referred to as CenoPCM, which can be directly added into traditional construction and building materials such as concrete to produce thermally active concrete. Prototype thermally active cement mortar integrated with the produced CenoPCM capsules have also been manufactured and characterized for its mechanical and microstructural properties. The characterizations showed that there was only minor reduction in strength and the mortar remained strong enough for building application. From this work, it is found that the produced

\footnotetext{
${ }^{*}$ Corresponding author. Tel.: +1-305-3486786; fax: +1-205-348-0783.

E-mail address: jwang@eng.ua.edu
} 
22 CenoPCM capsules have great potential to be added into construction materials for reducing

23 energy consumptions in buildings.

24 Keywords: Thermal energy storage, Phase change materials, Cenospheres, Microencapsulation,

25 Concrete

\section{Introduction}

It is estimated by the World Business Council for Sustainable Development that buildings are 28 responsible for at least $40 \%$ of energy use in many countries [1]. Energy use is increasing at an

29 annual rate of more than $3 \%$ in the U.S. alone, and is growing rapidly in countries such as China 30 and India. Worldwide energy consumption by buildings is expected to grow $45 \%$ over the next

3120 years. To cope with this challenging situation, efforts are needed to improve the energy

32 efficiency of buildings, which will not only relieve the energy demands, but also reduce the

33 environmental impacts associated with energy use, e.g. carbon dioxide emission.

Integrating phase change materials (PCMs) into building materials has been proposed to 35 address this need. PCMs can enhance the building energy efficiency through Thermal Energy

36 Storage (TES) and thermal regulation [2]. PCMs change their phase from solid to liquid and vice

37 versa at their phase change temperatures with large amounts of energy absorbed or released.

38 Thermal inertia (mass) of the building can be significantly increased by the integration of PCMs.

39 PCM-enhanced building envelopes have been studied with the following aspects in mind:

40 narrowing the gap between the peak and off-peak loads, saving building operation costs under

41 specific electricity tariffs, reducing diurnal temperature fluctuations concerning the occupants'

42 thermal comfort, and utilizing the free cooling at night for day peak cooling load shaving, along 
43 with others [3-6]. Significant energy savings for buildings can be achieved by PCMs, as

44 demonstrated by extensive studies [7,8].

45 Directly employing bulk PCMs into building materials suffers a few drawbacks. For example, 46 special latent heat devices or heat exchange surfaces are needed, which increases the associated

47 cost and thermal resistance between the PCM and the environment. Therefore, two methods are

48 commonly used to incorporate PCM into construction materials: microencapsulation of PCMs

49 and form-stable PCM composites. In the first method, PCMs are encapsulated within a

50 protection shell with a size between 1 and $300 \mu \mathrm{m}$ [9]. The produced microencapsulated PCMs

51 (MEPCMs) can preserve PCMs as long as the shell is intact during heating/cooling cycles.

52 MEPCMs provide a better utilization of PCMs within building components such as walls, roofs, 53 and floors, and within the building materials such as concrete, gypsum wallboard, plaster, and

54 mortar, among others. Compared with traditional PCMs, MEPCMs enjoy many advantages such

55 as their chemically-inert nature (due to the polymer barrier between the PCM and any other

56 material), the optimized heat transfer due to a high surface-area-to-volume ratio, and their ability

57 to be readily mixed into or coated onto other materials $[8,10]$.

However, MEPCMs also suffers a few drawbacks preventing their extensive application in 59 construction materials. First, the protection shell is usually made of polymer, which is of low 60 mechanical stiffness and strength. As a result, the mechanical stiffness and strength of the 61 construction materials can be significantly reduced by adding the PCMs microcapsules $[11,12]$.

62 Because of the low mechanical properties, PCMs microcapsules can also be broken during the 63 mixing of concrete, leading to the leakage of PCMs after melting. Second, the polymeric shell 64 also has low chemical and thermal stability, which can be deteriorated by UV light, oxidation, 65 and other aggressive chemicals. The shell can lose its stability when temperature exceeds its 
glass transition temperature, and it is flammable, and therefore cannot be adopted by US building

67 industry. Finally, the thermal conductivity of the polymer shells is very low, making thermal exchange between PCMs inside the shell and outside environment much more difficult [13,14].

69 In the second method, PCMs are first absorbed into porous materials such as light weight aggregates and diatomite particles to form stable composites, which are then added into the

71 construction materials [15-18]. While in absorbing PCM using porous particles, no protective

72 layers on the surface of the composites are available. As a result, PCMs can still leak from the

73 porous material during its melting process, leading to the reduction or loss of the claimed thermal 74 storage capacity. above barriers must be removed. To this end, this study proposes a novel method to encapsulate

77 PCMs with cenospheres, which are hollow fly ash particles generated in coal burning power 78 plants. Cenosphere particles have an aluminosilicate shell with high stiffness, high strength, and 79 a thickness of a few micrometers. The shell has a porous structure formed by gas inclusion and is covered by a layer of glass-crystalline nanosize film [19]. The hollow structure of the cenosphere

81 makes it an ideal material to encapsulate PCM. However, to introduce PCM into a cenosphere, 82 the glass-crystalline nanosize film on the surface of the cenosphere must be removed. This is 83 done by acid etching in this study. After removing the thin film, perforated cenospheres with 84 very small holes penetrating through the shell can be produced. By simply mixing the perforated 85 cenospheres in liquid PCM, liquid PCM can be loaded into the perforated cenospheres via a 86 vacuum impregnation process. A thin layer of silica coating is then applied to the PCM loaded 87 perforated cenospheres to prevent the possible leakage of liquid PCMs. The produced PCM 88 microcapsules with cenosphere shell are therefore referred to as CenoPCM in this study. 
With cenospheres, the expensive process to synthesize the polymer shell used in existing

MEPCMs is therefore eliminated. As a result, the cost to produce PCM microcapsules can be significantly reduced with this new microencapsulation method. In addition, thanks to its hard, inorganic shell, CenoPCM also enjoys many distinct mechanical, chemical, and thermal advantages over existing polymer encapsulated PCM: (1) cenospheres exhibits much better mechanical properties than the polymeric shells used in existing MEPCMs. The crushing strength of cenospheres are in the ranges from 10-20 MPa [20], which means cenospheres will not be easily damaged during handling and are able to withstand mechanical loading to some extent; (2) cenosphere shell has high thermal and chemical stability that can resist chemicals, lights, and high temperature; (3) since the shell of cenospheres are inorganic composed mainly of polycrystalline dense mullite, their thermal conductivity is much higher than the polymeric shells in existing MEPCMs. With all these advantages, encapsulating PCM with cenospheres is possible to eliminate the major barriers preventing the extensive application of MEPCMs in traditional building materials.

In this work, n-octadecane was selected as PCM to manufacture CenoPCM because of its good performance of heat energy storage and thermal regulation in an appropriate phase change range $\left(23-28^{\circ} \mathrm{C}\right)$ which is comfortable for the human body. The morphological-chemical performance and thermal energy storage properties of produced CenoPCM were characterized by XRF, SEM, TG, and DSC analysis techniques. A prototype thermally active cement mortar integrated with CenoPCM was also developed and evaluated for its physical, mechanical, and microstructural features. These analysis results showed the superior thermal and mechanical performance of the CenoPCM itself as well as mortar integrating CenoPCM. 


\section{2. Materials and methods}

\section{2.1. Materials}

114 Reagent grade n-octadecane $\left(\mathrm{C}_{18} \mathrm{H}_{38}\right)$, ammonium fluoride $\left(\mathrm{NH}_{4} \mathrm{~F}\right)$ with a purity of $96 \%$, and $11550 \%$ silicon dioxide in water (silica sol) were purchased from Alfa Aesar Company, USA.

116 Hydrochloric acid ( $\mathrm{HCl})$ was commercially obtained from VWR International (USA). Calcium

117 gluconate gel was always present during handling of hydrofluoric based acid solution (1.0 M $\left.118 \mathrm{NH}_{4} \mathrm{~F}-1.2 \mathrm{M} \mathrm{HCl}-\mathrm{H}_{2} \mathrm{O}\right)$.

119 Cenospheres used in this research were obtained from CenoStar Corporation (USA). It has 120 sizes between 10 and $200 \mu \mathrm{m}$ with $\mathrm{d}_{10}=59.4 \mu \mathrm{m}, \mathrm{d}_{50}=96.7 \mu \mathrm{m}$ and $\mathrm{d}_{90}=137.2 \mu \mathrm{m}$, as shown 121 in Fig. 1. Table 1 shows the chemical composition of cenospheres used, gained by X-ray 122 fluorescence (XRF) analysis. According to the table, the cenospheres contain up to $57.35 \mathrm{wt} \%$ 123 silicon dioxide, $31.93 \mathrm{wt} \%$ aluminum oxide, and lower amounts of iron, calcium, titanium, 124 magnesium, sodium, potassium, and boron oxides, which range from less than one to three 125 percent. The composition of Type I Portland cement used for casting mortar is also listed in 126 Table 1, which was phased from Sakrete (USA). cenospheres with silica sol. 


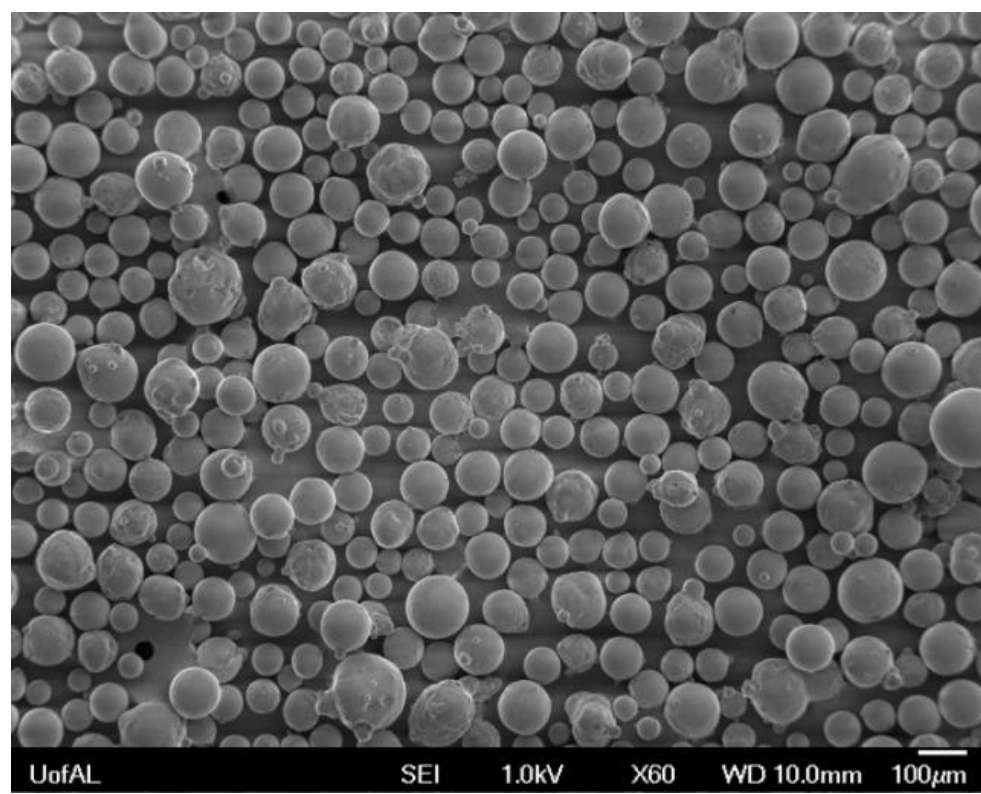

Fig. 1. As-received cenospheres with typical size from 10 to $200 \mu \mathrm{m}$.

Table 1 Chemical composition of cenospheres and Type I Portland cement.

\begin{tabular}{lll}
\hline Compound $(\%)$ & $\begin{array}{l}\text { As-received } \\
\text { Cenospheres }\end{array}$ & $\begin{array}{l}\text { Type I Portland } \\
\text { Cement }\end{array}$ \\
\hline $\mathrm{SiO}_{2}$ & 57.35 & 22.93 \\
$\mathrm{Al}_{2} \mathrm{O}_{3}$ & 31.93 & 4.68 \\
$\mathrm{CaO}$ & 0.44 & 64.04 \\
$\mathrm{Fe}_{2} \mathrm{O}_{3}$ & 2.27 & 2.41 \\
$\mathrm{TiO}_{2}$ & 1.17 & 0.20 \\
$\mathrm{MgO}^{\mathrm{Na}}$ & 0.54 & 3.38 \\
$\mathrm{~K}_{2} \mathrm{O}$ & 0.54 & 0.23 \\
$\mathrm{P}_{2} \mathrm{O}_{5}$ & 1.40 & 0.76 \\
$\mathrm{MnO}$ & 0.06 & 0.08 \\
\hline
\end{tabular}

\subsubsection{Perforate cenospheres with acid etching}

Cenosphere particle has an aluminosilicate shell with high stiffness and strength and a

139 thickness in a few micrometer (Fig. 2(a)). The shell has a porous structure formed by gas

140 inclusion and is covered by a glass-crystalline nanosize film, which is shown in Fig. 2 (b). The 
141 hollow structure of cenospheres makes it an ideal material to encapsulate PCM. However, to

142 introduce PCM into cenospheres, the film covering the surface must be removed. This can be

143 done by acid etching the cenospheres [21,22]. To this end, approximately $12 \mathrm{~g}$ of cenospheres

144 was soaked into $250 \mathrm{~mL}$ of $1.0 \mathrm{M} \mathrm{NH}_{4} \mathrm{~F}-1.2 \mathrm{M} \mathrm{HCl}-\mathrm{H}_{2} \mathrm{O}$ solution for 2 hours with occasional

145 stirring. The specific gravity of cenospheres used is about $0.75 \mathrm{~g} / \mathrm{cm}^{3}$, thus $12 \mathrm{~g}$ of cenospheres

146 corresponded to a volume of $16 \mathrm{~mL}$. This made the volume ratio of solid to liquid to $1: 15$ in this

147 acid treatment, which was among the range adopted by other researchers [21,22]. Occasional

148 stirring was applied instead of continuous one to prevent the possible damage of the cenospheres

149 during stirring. To compensate for this mild stirring process, longer treatment time was used (2

150 hours). By the end of this treatment, more than $95 \%$ of cenosphere sank to the bottom of

151 container (Fig. 3(b)), which was floating on the surface of acid solution at the beginning (Fig.

152 3(a)). The settlement of cenospheres indicates the completion of perforation. After etching, the

153 perforated cenospheres were vacuum filtered and rinsed with $1500 \mathrm{~mL}$ of water, followed by

154 dried in an oven at $150{ }^{\circ} \mathrm{C}$. For this etching treatment, further work will be implemented on

155 optimizing the etching parameters in the future, including acid concentration, solid to liquid ratio,

156 and treatment time, among others.

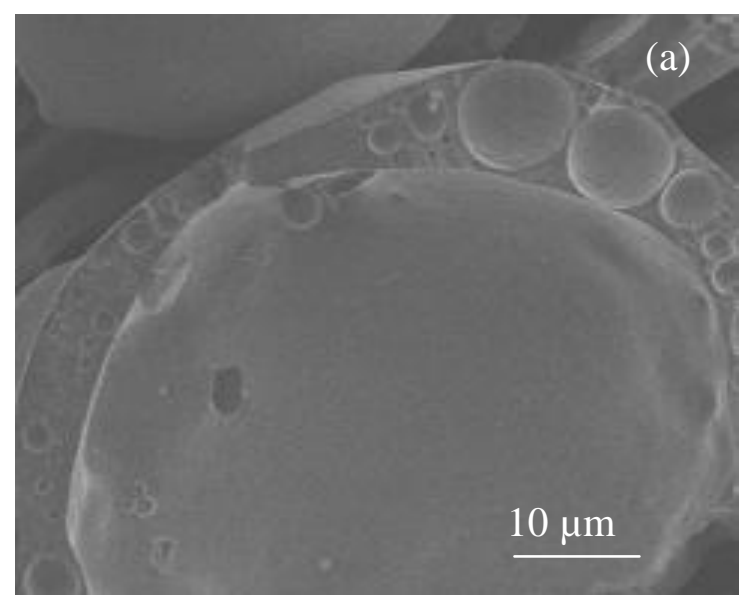


Fig. 2. Microstructure of cenospheres under SEM observation: (a) porous shell of cenospheres; and (b) impermeable shell before etching.

\subsubsection{Load PCM into perforated cenospheres}

171 weighted and placed into a flask. The flask was exposed to vacuum pressure of approximately

$17280.5 \mathrm{kPa}$ for $\sim 2$ hours [23]. Melted n-octadecane with volume as three times as the cenospheres

173 was then introduced into the flask. Operation of the vacuum was stopped and air was allowed

174 back into the flask to drive the n-octadecane into the hollow space inside the cenospheres for

175 about 30 minutes. The completion of loading was achieved when the cenospheres settled down at

176 the bottom of the flask. Before allowing the air back, all cenospheres were floating on the surface

177 of liquid n-octadecane. During the whole impregnation process, the flask was heated by a hot

178 plate with the temperature set at $60^{\circ} \mathrm{C}$. This temperature was high enough to keep the PCM in

179 liquid status once it was introduced into the flask. This means the cenospheres were soaked in

180 liquid PCM all the time when they contacted with each other. With completion of loading, flask 

water. Then the cenospheres were left to be dried in air for about 48 hours.
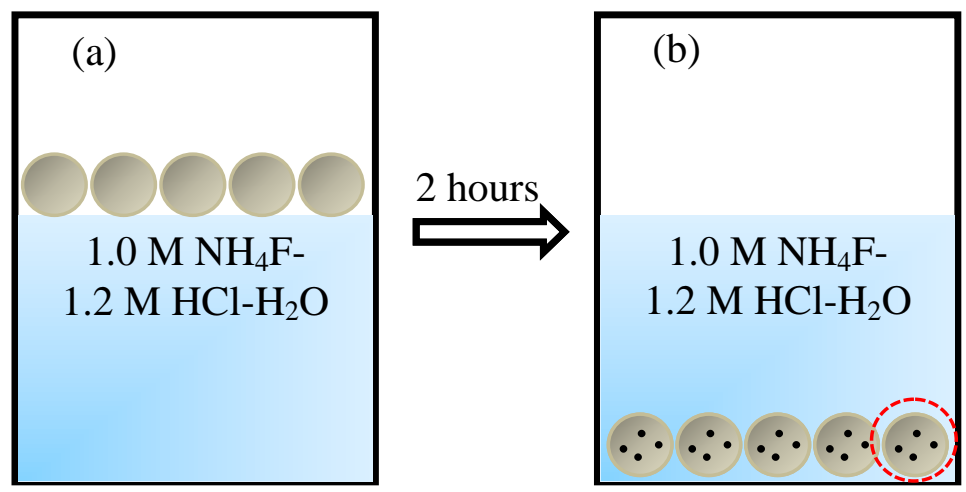

Fig. 3. Acid etching of cenospheres: (a) at the beginning, cenospheres floated on the surface of acid solution; (b) by the end of 2 hours' etching, cenospheres were perforated and sank to the bottom of the container.

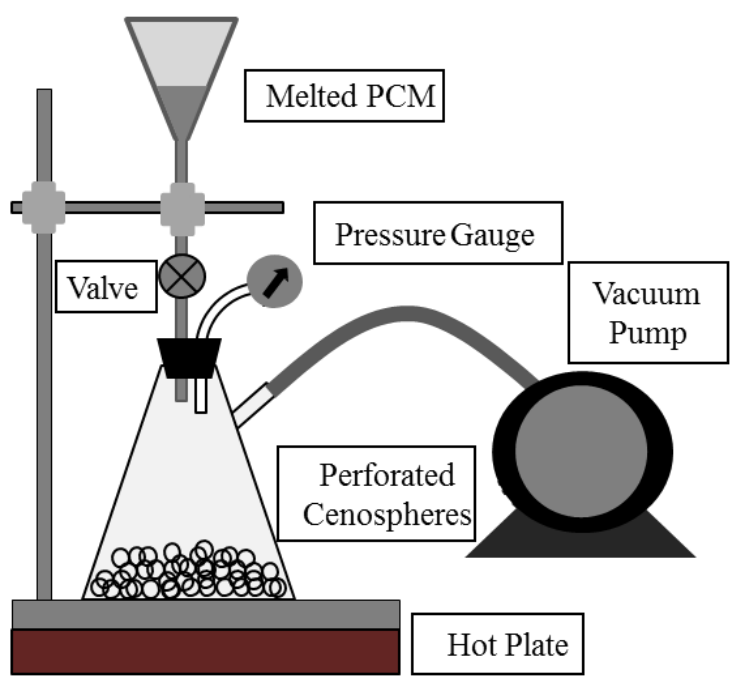

Fig. 4. Schematic drawing of vacuum loading setup.

\subsubsection{Seal PCM loaded cenospheres with silica sol}

To prevent the possible leakage of the loaded PCM, it is necessary to seal the pores created on the shell of perforated cenospheres. In this work, the pore sealing was done by coating a thin 
192 layer of silica on the cenosphere shell. This coating will also strengthen the cenospheres.

193 Additionally, the coated silica layer would serve as a source of silica that can react with calcium

194 hydroxide formed from cement hydration [24,25]. The reaction will produce $\mathrm{C}-\mathrm{S}-\mathrm{H}$ gel, which is

195 the main bonding material that provides concrete strength. Thus, with the silica coating,

196 CenoPCM is possible to achieve a better bonding with the adjacent mortar materials when it is

197 integrated into mortar. The silica coating was simply done by soaking the PCM loaded

198 cenospheres into $25 \%$ silica sol for about 20 minutes at room temperature. The volume ratio

199 between cenospheres and silica sol was about 1:3, and during soaking the magnetic stirring with

200 a speed of $60 \mathrm{rpm}$ was occasionally applied for more homogenous effect. Then the coated

201 cenospheres were filtered and dried over air. More work will be carried out in the future to find

202 the optimal coating parameters, including the content of cenospheres and silica sol, stirring speed,

203 and soaking, among others.

204

205

206

207

208

209

210

211

212

213 214 atmosphere.

\subsection{Characterization of CenoPCM}

The morphology and microstructure of as-received cenospheres (see Figs. 1 and 2), perforated cenospheres, PCM loaded cenospheres (unsealed CenoPCM), and sealed CenoPCM were investigated using a JOEL 7000 FE scanning electron microscope (SEM). The microscope was operated at low accelerating voltage $(1 \sim 3 \mathrm{kV})$ and $10 \mathrm{~mm}$ working distance with a spot size of medium 8 . The phase change temperatures and enthalpies of the prepared CenoPCM were determined using a DSC instrument (Q2000 from TA Instruments) at a scanning rate of $5^{\circ} \mathrm{C} / \mathrm{min}$ scanning rate. The scanning range was set at 10 to $50{ }^{\circ} \mathrm{C}$. Thermogravimetric analysis (TGA) was performed to examine the thermal stability of the produced CenoPCM by Q500 (from TA instruments) at a heating rate of $20^{\circ} \mathrm{C} / \mathrm{min}$ between room temperature and $700{ }^{\circ} \mathrm{C}$ under nitrogen 


\subsection{Evaluation of mortar with CenoPCM}

217 Both sealed and unsealed CenoPCM was integrated into mortar to evaluate its effects on

218 mortar's physical, mechanical, and microstructural properties. The mix proportions are listed in

219 Table 2. There were three mix proportions used, the reference mortar without CenoPCM and the

220 mortars integrated with 3\% PCM by total weight of the mortar through sealed or unsealed

221 CenoPCM. For all the mixes, the water to cement and sand to cement ratio are 0.55 and 3.0,

222 respectively. In the reference mortar without CenoPCM, fine sand that passed through No.30

223 sieve $(\sim 600 \mu \mathrm{m})$ was added in the same volume as occupied by CenoPCM in 3\% mortar. The

224 mean particle size of the fine sand was about $300 \mu \mathrm{m}$, estimated from the sieve analysis results.

225 With the known specific gravity of the materials used (3.15 for cement, 2.7 for sand, 0.75 for

226 cenospheres) and loading capacity of cenospheres with PCM (175.02 wt.\% obtained from TGA),

227 the needed amount of each material can be easily calculated, and the results are shown in Table 2.

228 It has to be pointed out that no superplasticizer was used in the mix proportions. This is because

229 the mixes already showed similar flowability and workability during mixing and casting without

230 superplasticizers. Thus the adjustment of superplasticizer was not required in this study.

231 Table 2 Mix proportions of mortars.

\begin{tabular}{|c|c|c|c|c|}
\hline \multirow[t]{2}{*}{ Constituent } & \multicolumn{2}{|c|}{ Reference Mortar } & \multicolumn{2}{|l|}{$3 \%$ Mortar } \\
\hline & Volume $\left(\mathrm{m}^{3}\right)$ & Mass (kg) & Volume $\left(\mathrm{m}^{3}\right)$ & Mass $(\mathrm{kg})$ \\
\hline Cement & 0.15 & 480 & 0.15 & 480 \\
\hline Water & 0.26 & 264 & 0.26 & 264 \\
\hline Sand & 0.53 & 1440 & 0.53 & 1440 \\
\hline Fine Sand & 0.05 & 135 & 0 & 0 \\
\hline $\begin{array}{l}\text { Unsealed or } \\
\text { Sealed CenoPCM }\end{array}$ & 0 & 0 & 0.05 & 106 \\
\hline $\begin{array}{l}\text { Total \% PCM in } \\
\text { Mortar }\end{array}$ & 0 & 0 & 5 & 3 \\
\hline
\end{tabular}


Cement, water, and sand were firstly mixed together according to the ASTM C305 [26].

233 Then CenoPCM or fine sand was introduced to the mixture and mixed for additional 2 minutes at

234 slow speed to produce homogenous mortar. Thereafter, the mortar was cast into cylindrical

235 molds with a diameter of $50 \mathrm{~mm}$ and height of $100 \mathrm{~mm}$, and then compacted using a vibration

236 table. After being seal cured for 24 hours, the samples were demolded and cured under water at a

237 controlled temperature of $23 \pm 1^{\circ} \mathrm{C}$ till the designated ages of 3,7 , and 28 days. At each age,

238 compression test was carried out on three samples according to the ASTM C109 [27]. The

239 mortar samples were prized into pieces for SEM observation as well.

\section{3. Results and discussion}

241 3.1 Microstructure of perforated cenospheres, unsealed CenoPCM, and sealed CenoPCM

242 The original cenospheres represent a silicate-alumina-iron multiple component system with

243 the surface covered by glass-crystalline nanosize film. To use cenospheres for

244 microencapsulation, this layer of film should be removed to make the inner hollow space

245 accessible for PCM. In current work, this was achieved by etching the cenospheres with a

246 solution of $1.0 \mathrm{M} \mathrm{NH}_{4} \mathrm{~F}-1.2 \mathrm{M} \mathrm{HCl}-\mathrm{H}_{2} \mathrm{O}$ for 2 hours. Table 3 lists the chemical composition of

247 cenospheres after this acid treatment. Compared to the original composition (Table 1), the

248 content of alumina was increased significantly from 31.93 to $35.00 \%$ in the perforated

249 cenospheres. This is because alumina was not subjected to the etching action [21], while the

250 silica and iron deposits on cenospheres were dissolved by the hydrofluoric based acid system.

251 The dissolution resulted in about $8.77 \%$ weight loss of the cenospheres shell. This small amount

252 of dissolution indicates that the acid etching is able to perforate the shell without compromising

253 the shell's mechanical strength. 
Fig. 5 shows the microstructure of the perforated cenospheres. It can be seen clearly that 255 compared to the original cenospheres (Fig. 2(b)), the wall structure changes significantly, going 256 from a solid to a spongy porous one. This indicates that the glass-crystalline film has been 257 removed from the cenosphere surface by the applied acid treatment. From Fig. 5, it is also seen 258 that the majority of pores created on cenosphere shell are smaller than $500 \mathrm{~nm}$, with occasional 259 pores with micron size $(<2 \mu \mathrm{m})$. These pores, together with the porous structure of cenosphere 260 shell formed by gaseous inclusions, perforated the cenospheres, providing paths for loading 261 liquid PCM.

262 Table 3 Chemical composition of perforated cenospheres produced by acid etching.

\begin{tabular}{cc}
\hline Compound (\%) & Perforated Cenospheres \\
\hline $\mathrm{SiO}_{2}$ & 57.81 \\
$\mathrm{Al}_{2} \mathrm{O}_{3}$ & 35.00 \\
$\mathrm{CaO}$ & 0.33 \\
$\mathrm{Fe}_{2} \mathrm{O}_{3}$ & 2.13 \\
$\mathrm{TiO}_{2}$ & 1.15 \\
$\mathrm{MgO}$ & 0.51 \\
$\mathrm{Na}_{2} \mathrm{O}$ & 0.52 \\
$\mathrm{~K}_{2} \mathrm{O}$ & 1.32 \\
$\mathrm{P}_{2} \mathrm{O}_{5}$ & 0.05 \\
\hline
\end{tabular}

263

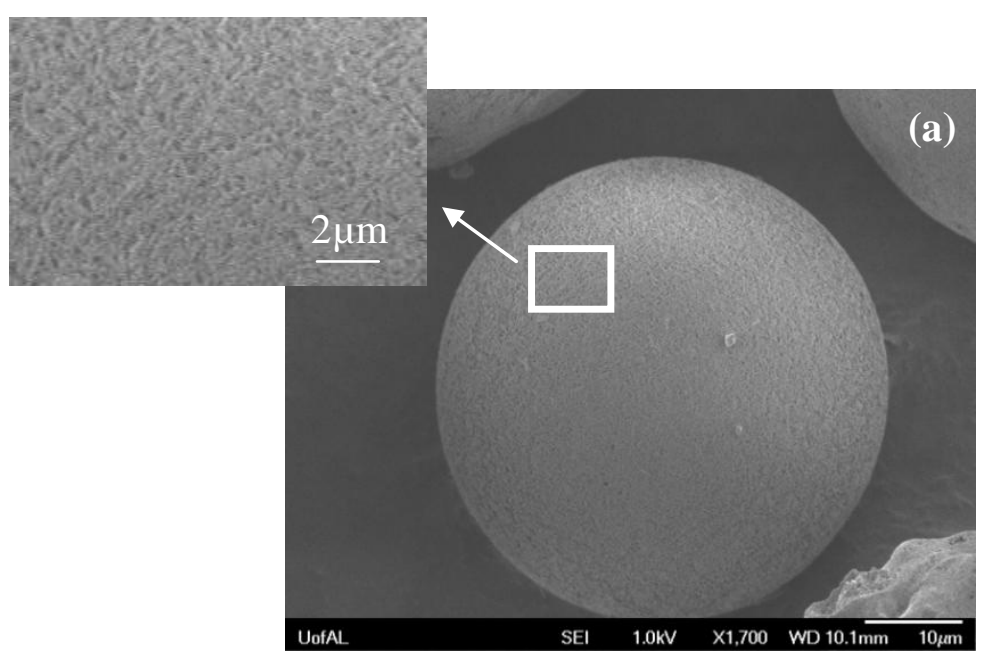




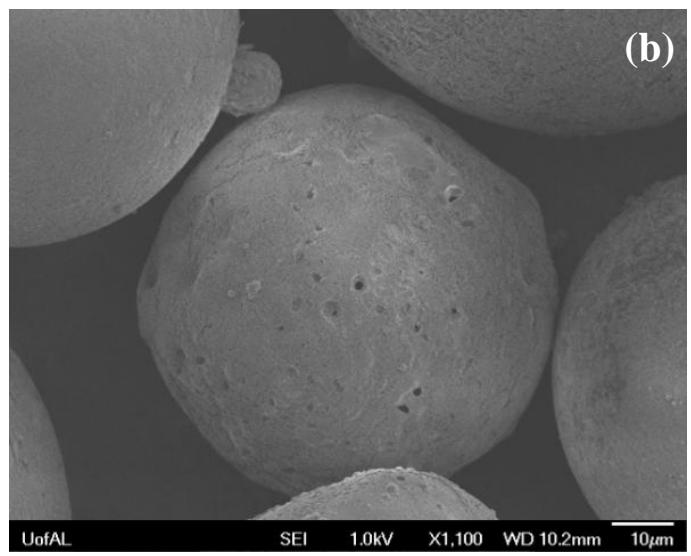

Fig. 5. SEM microphotographs of the perforated cenospheres after being etched with $1.0 \mathrm{M}$ $\mathrm{NH}_{4} \mathrm{~F}-1.2 \mathrm{M} \mathrm{HCl}-\mathrm{H}_{2} \mathrm{O}$ solution for 2 hours.

269 demonstrated in Fig. 6. From Fig. 6(a), it can be found that almost all the PCM loaded

270 cenospheres are intact. This means that the vacuum pressure applied $(80.5 \mathrm{kPa})$ for PCM

271 impregnation did not destroy the shells, suggesting both the applicability of vacuum loading and

272 high mechanical strength of perforated cenospheres. To expose the internal space of cenospheres,

273 the spheres were carefully crushed by a small piece of slug. Examination of these purposely

274 broken cenospheres (Fig. 6(b)) suggests that they all are filled with PCM. For clarity, the ones in

275 the upper right corner and center of Fig. 6(b) are enlarged and displayed in Figs. 6(c) and (d),

276 respectively. It is interesting to see from these two figures, especially Fig. 6(d), that the detached

277 pieces have not yet completely fell down from their original positions in the cenospheres. This

278 indicates that the particle is damaged during the manual broken process right before SEM

279 observation, instead of being originally broken before or during impregnation. Otherwise, these

280 pieces would fully fall apart into surroundings. From the gaps between these broken pieces, it

281 can be seen that the cenospheres are fully loaded with PCM that has a layered structure. 
The last step involved in preparing CenoPCM was to seal the perforated cenospheres to prevent the possible leakage of PCM during its service life. This coating was applied by simply soaking the PCM loaded cenospheres into silica sol. Fig. 7 shows the cenospheres being coated 285 with silica sol. Fig. 7(b) displays the same cenosphere particle in the center of Fig. 7(a) but at a 286 higher magnification. According to Fig. 7(b), the surface texture of the cenosphere has been 287 coarsened with coating, compared to the ones without coating (Figs. 5 and 6). The silica particles 288 from the sol connect with each other, forming a layer of coating covering the cenosphere shell. 289 One may also notice that a few pores with sizes of about $2 \mu \mathrm{m}$ are still visible on the shell after 290 cenosphere being coated, which indicates that the coating layer is thin and not thick to the extent 291 that can cover the micron size pores. Increased thickness of the coating will be facilitated in the 292 future research by optimizing the coating parameters, including the content of cenospheres and 293 silica sol, stirring speed, and soaking time, among others.
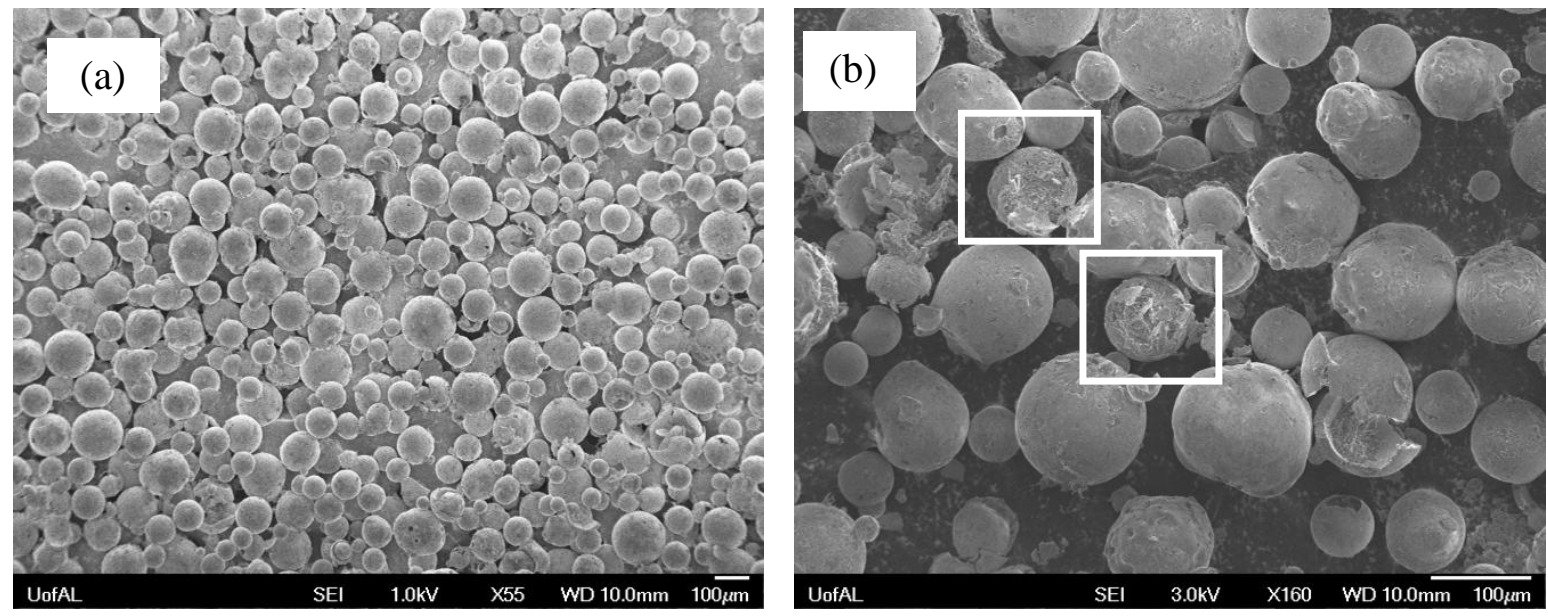



Fig. 6. (a) Microstructure of cenospheres loaded with PCM before manual crushing; (b), (c), and (d) manually crushed cenospheres whose internal space is fully loaded with PCM.
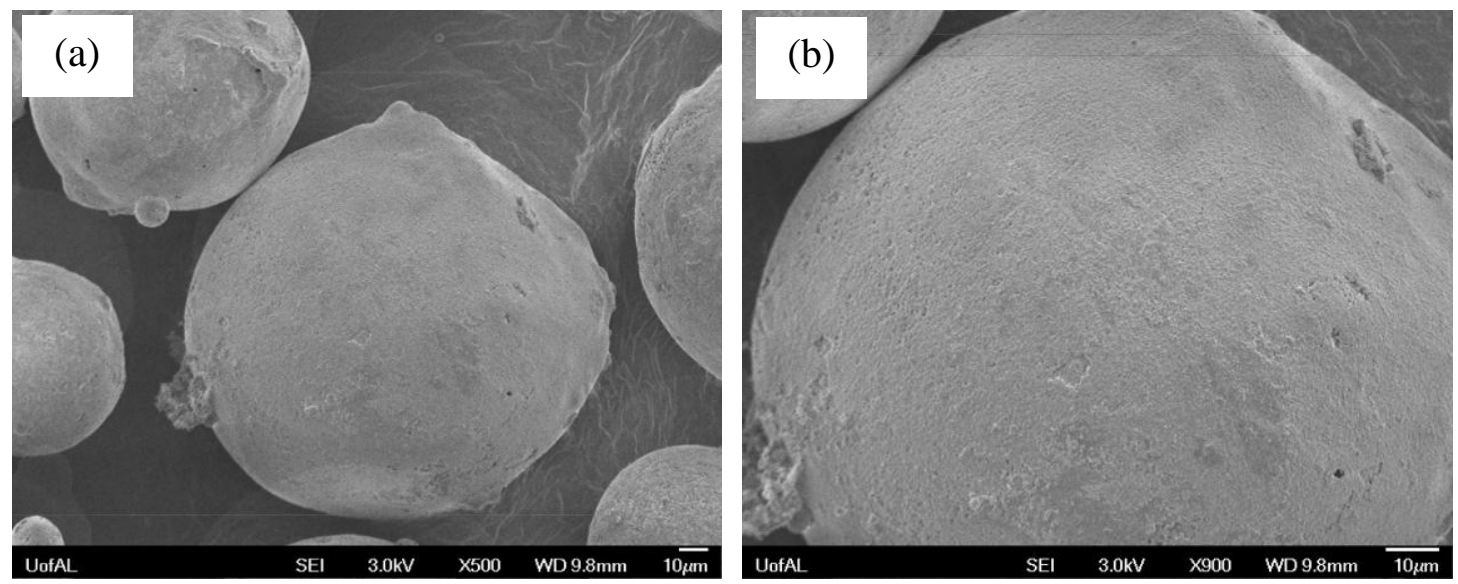

Fig. 7. Coating of a silica layer on the surface of perforated cenospheres loaded with PCM.

\subsection{Thermal stability and phase-change performance of CenoPCM}

Thermal stability is a significant factor in evaluating CenoPCM for the application of heat

$$
\text { investigated by means of TGA, which presents the mass loss of samples and corresponding }
$$

which was attributed to the decomposition of the microencapsulated PCM (n-octadecane) [28].

Decomposed PCM vapor was quickly lost from the perforated cenospheres, and this process 
continued till temperature reached $220{ }^{\circ} \mathrm{C}$. After this temperature, no further weight loss can be

309 observed for the CenoPCM sample, suggesting that all n-octadecane inside the perforated

310 cenospheres had been evaporated. The residual weight of the sample is the weight of the

311 perforated cenosphere shell. The curve shows that the loaded PCM accounts for approximately

$31263.64 \%$ by total weight of the produced CenoPCM, which corresponds to as high as $175.02 \%$

313 loading capacity of perforated cenospheres with n-octadecane. From the curve, it is also seen that 314 there is no degradation occurring in the cenosphere shell within the testing temperature range $315\left(700{ }^{\circ} \mathrm{C}\right)$, implying the much higher thermal stability of the cenosphere than polymer shells used 316 in existing MEPCMs. The polymer based microcapsules would have another obvious weight loss 317 at the decomposition temperature of the shell materials [28].

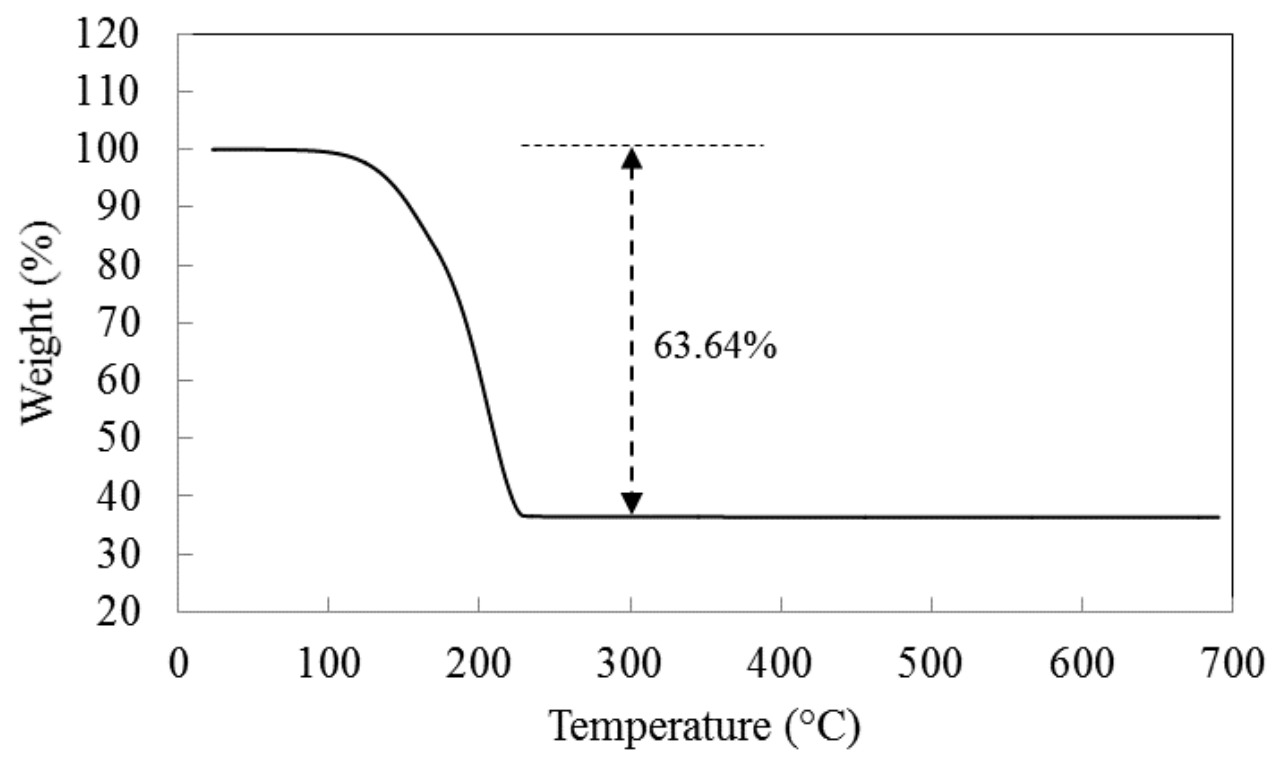

Fig. 8. TGA thermogram of the produced CenoPCM.

The phase change behaviors of the prepared CenoPCM (unsealed) are evaluated by DSC, and its thermograph is presented in Fig. 9, where the upward peak indicates the exothermic process while the downward corresponds to the endothermic one. The phase change temperatures (i.e. $T_{\mathrm{m}}$ 
324 and $T_{\mathrm{c}}$ ) of the CenoPCM obtained from the DSC measurement are also displayed in the figure.

$325 T_{\mathrm{m}}$ or $T_{\mathrm{c}}$ is given by the intersection of the tangent through the point of maximum slope on the 326 melting or crystallization front peak and the extrapolated baseline on the DSC heating and

327 cooling curves, respectively. The produced CenoPCM has a crystallization peak $T_{\mathrm{c}}$ at around

$32822.7^{\circ} \mathrm{C}$, and it is as well observed that the peak is not that sharp. This is because n-octadecane

329 has two types of structures that crystallize at slightly different temperatures, generating two

330 exothermic peaks that are overlapped together [28]. On the contrary, the n-octadecane shows

331 only one single, well-defined endothermic peak on the heating thermogram with $T_{\mathrm{m}}$ at $23.8{ }^{\circ} \mathrm{C}$.

332 The phase-change enthalpies [i.e., the fusion heat $\left(\Delta H_{\mathrm{m}}\right)$ and crystallization enthalpy $\left(\Delta H_{\mathrm{c}}\right)$ ] of

333 the CenoPCM are deduced from the DSC measurement and also shown in Fig. 9. The CenoPCM

334 has a $\Delta H_{\mathrm{m}}$ of $119.83 \mathrm{~J} / \mathrm{g}$ and $\Delta H_{\mathrm{c}}$ of $128.84 \mathrm{~J} / \mathrm{g}$, respectively.

335

336

337

338

339

340

341

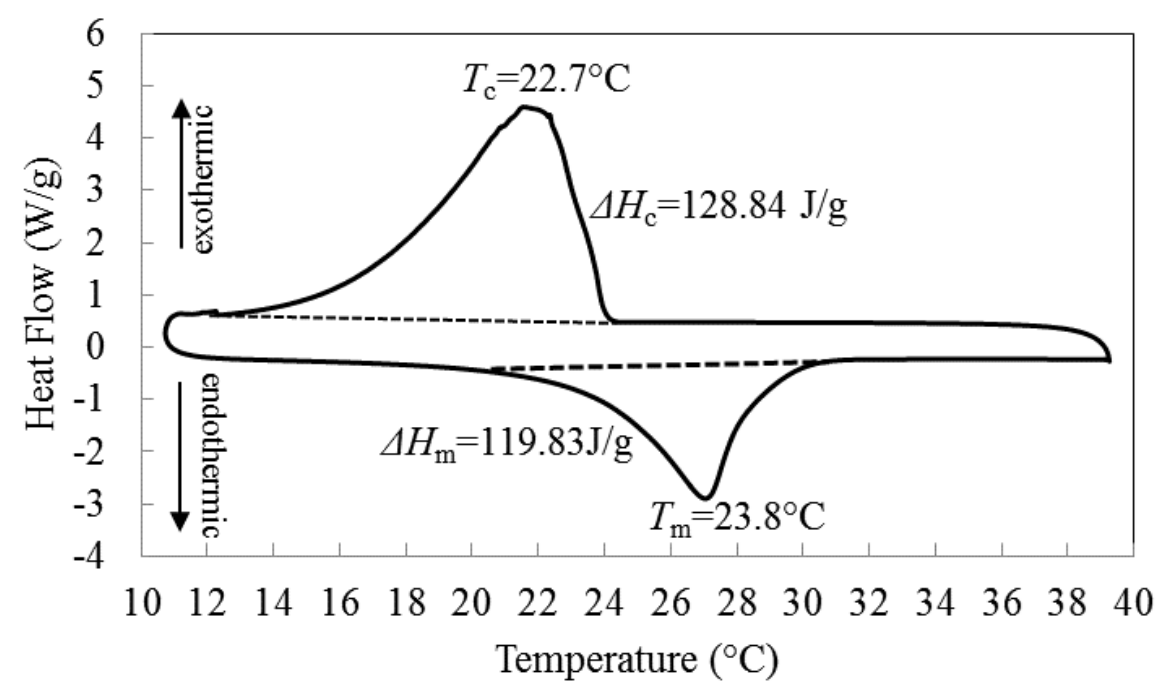

Fig. 9. DSC thermograms of the produced CenoPCM.

\subsection{Mechanical property of cement mortar incorporating CenoPCM}

To examine the mechanical performance of CenoPCM in construction materials, the compressive strength of mortar with and without CenoPCM is measured and displayed in Fig. 10. From this figure, it can be seen that compared to the control mortar, addition of $3.0 \mathrm{wt} . \%$ of PCM 
342 through either unsealed or sealed CenoPCM (corresponding to $\sim 4.7$ wt.\% of CenoPCM) resulted

343 in the strength loss at all the ages studied, which was around $15.6 \%$ and $5.6 \%$ at 28 days,

344 respectively. But both mortars remain strong enough for structural application. The lowest

345 strength in the mortar containing unsealed CenoPCM could be partially attributed to the PCM

346 absorbed on the shell surface. The PCM may interact or crosslink with unreacted cement

347 constituents and hydration products, which potentially reduces the strength $[11,12]$. After the

348 CenoPCM being coated with a layer of silica sol, the strength has been recovered, which reached

$34994.4 \%$ of the control mortar at 28 days. This could be caused by the fact that the silica sol seals

350 the perforated pores on the shell, densifying and strengthening the CenoPCM particles. In the

351 meantime, the coated silica sol may react with calcium hydroxide, producing $\mathrm{C}-\mathrm{S}-\mathrm{H}$ gel that can

352 enhance the bonding between the CenoPCM microcapsules and surrounding mortar

353 microstructure. As comparison, after adding 3wt.\% of CIBA's and BASF's phase change

354 materials microcapsules, the strength reduction of mortar was about $44 \%$ [11] and $47 \%$ [12] at

35528 days, respectively. This is because the polymer encapsulated PCMs do not present a

356 mechanical resistance, their inclusions into concrete weaken the overall strength of the materials

$357[11,12]$. On the contrary, the much lower strength reduction in CenoPCM mortars should be

358 attributed to the high mechanical strength properties of the cenospheres shell. As given by the

359 manufacturer, $90 \%$ of the cenospheres used in current work can resist compression up to 22.06

$360 \mathrm{MPa}$.

The microstructure of mortar with unsealed CenoPCM was investigated. The samples were

362 prepared as small fragment from the failed cylindrical mortar specimens after compression tests.

363 The fragments were mounted on Al stubs with carbon cement, vacuum dried for 24 hours, $\mathrm{Pt}$

364 sputter coated, and imaged in the high vacuum SEM mode. Evidence of CenoPCM particles was 
found to be well distributed throughout the hardened microstructure, and it was apparent in the form of intact CenoPCM particles (labelled as "A" in Fig. 11), hemispherical voids

367 (characteristic of CenoPCM particle shape and surface texture) from where CenoPCM particles 368 were present during curing then later pulled out because of compression (labelled as "B" in Fig. 369 11), or damaged CenoPCM particles still occupying the voids (labelled as "C" in Fig. 11).

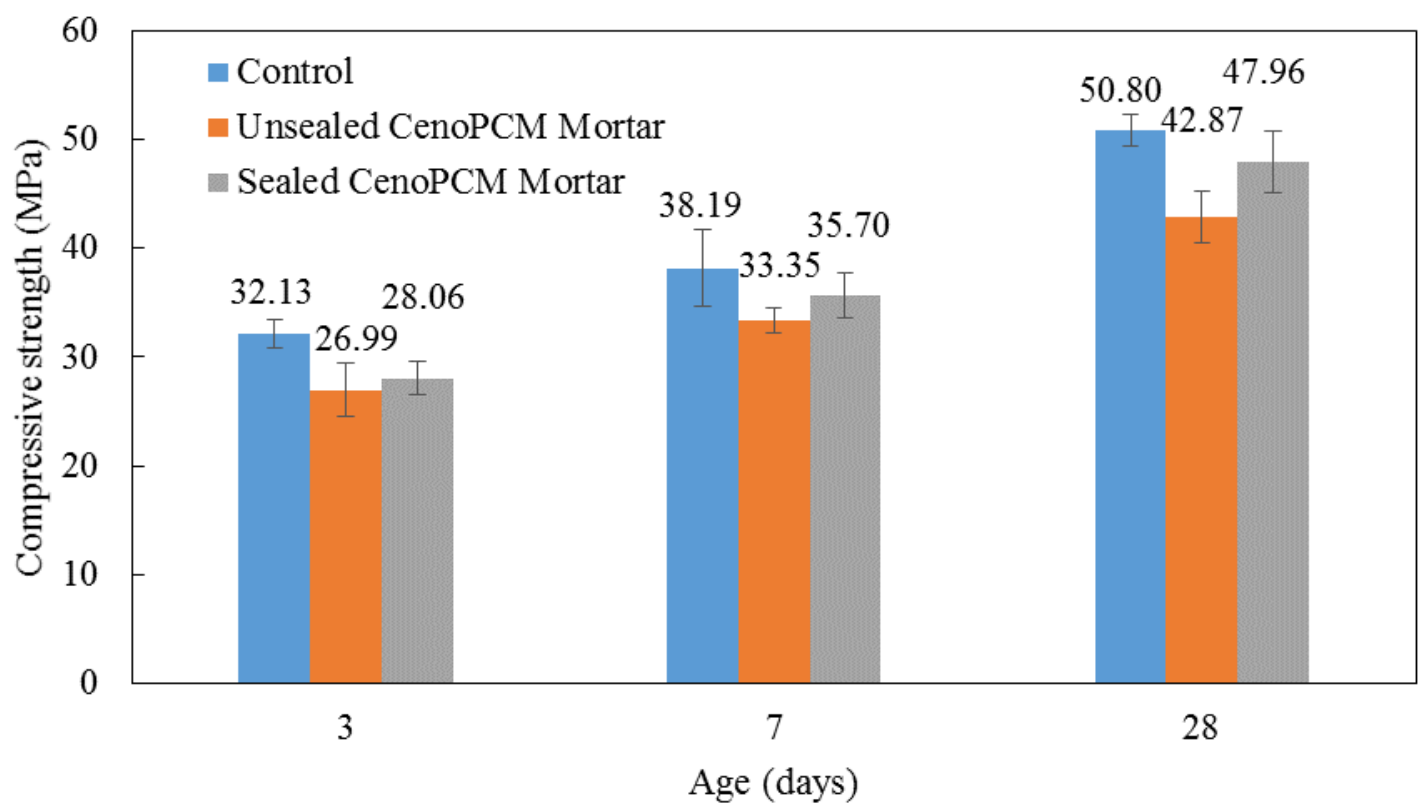

Fig. 10. Compressive strength of mortars with and without CenoPCM at different ages.

372 Close-ups of typical B and C spots shown in Fig. 11 are shown in Fig. 12 (a) and (b),

373 respectively, to illustrate the difference of these two microstructures. From these two images, it 374 is clear to see that the spherical voids (Fig. 12 (a)) do not have the characteristic porous wall as 375 seen in the damaged cenospheres. But the voids have the typical cenospheres' spherical shape 376 and surface texture, so they were not air void induced during mortar mixing. Instead, they 377 appeared to be created by the bursting of cenospheres, which were the result of CenoPCM 378 particle pre-curing embedment followed by post-loading pull-out. The damaged CenoPCM 379 remnants (Fig. 12 (b)) are not because that the CenoPCM were damaged during mortar mixing or 
compaction, but they are merely a consequence of the compression cutting its way through the capsules because of their weaker strength when compared to the surrounding matrix. If

382 CenoPCM was broken during mortar mixing or compaction, at least some of the damaged

383 CenoPCM particles would be filled with mortar instead of being hollow. But there is little

384 evidence found for such broken particles. The survival of CenoPCM particles during mortar

385 manufacturing should be attributed to the high crushing strength of cenospheres (10-20MPa).

386 Compared to those MEPCMs which were easily damaged [12], CenoPCM is more applicable to

387 be used in concrete materials for thermal energy storage given to its superior mechanical

388 performance.



Fig. 11. SEM micrograph of CenoPCM (unsealed) mortar fracture surface showing (A) intact during curing then later pulled out because of compression, and $(\mathrm{C})$ damaged, hollow CenoPCM particles. 

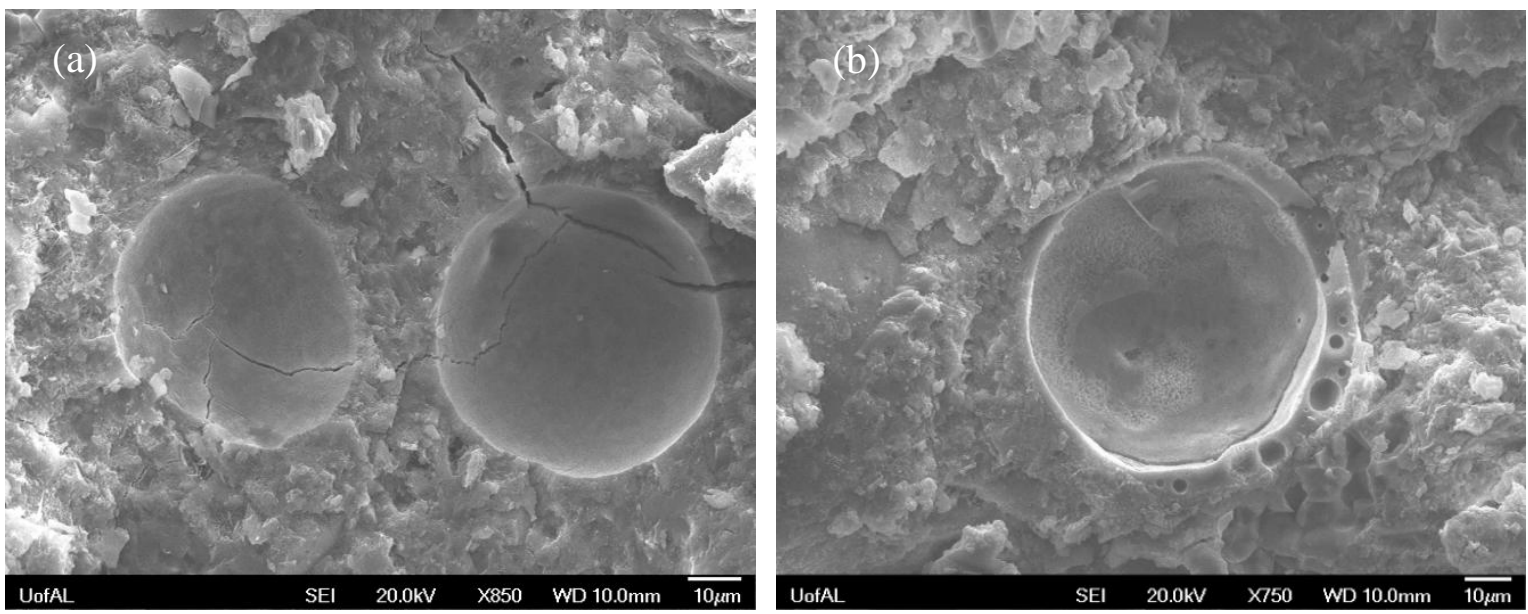

396

397

398

399

400

401

402

403

404

405

406

407

408

409

410

411

412

Fig. 12. (a) SEM images showing hemispherical voids due to cenosphere pulled out; (b) A damaged CenoPCM particle (unsealed) in the mortar at the hydration age of 28 days.

\section{Conclusions}

A novel technology to encapsulate PCM into cenospheres has been successfully

demonstrated in this paper. By removing the nanosize glassy-crystalline film covering the

cenosphere shell using chemical etching, perforated cenospheres can be produced. PCM in liquid phase can be easily loaded into the perforated cenospheres to produce PCM microcapsules

(CenoPCM), which not only can store and release heat at the human comfort zone $\left(T_{c}=21.57^{\circ} \mathrm{C}\right.$ and $T_{m}=23.8^{\circ} \mathrm{C}$ ), but also possesses high thermal storage and release capacities. Integration of 4.7\% unsealed CenoPCM (corresponding to 3.0\% pure PCM inclusion) into mortar caused 10$15 \%$ loss of compressive strength. However, such reduction in strength of mortar can be recovered by coating the CenoPCM with a thin layer of silica sol on the surface.

The new microencapsulation method developed in this study of PCM using cenospheres enjoys many advantages over currently available polymer-based MEPCMs, including low cost, high thermal energy storage capacity and stability, and high mechanical properties. This study also suggests that CenoPCM can be a promising candidate for adding thermal energy storage to 
413 traditional construction materials such as concrete. More work will be carried out to evaluate the

414 thermal performance, durability, and inflammability of concrete or mortar incorporating

415 CenoPCM.

416 Acknowledgements

417 The financial supports from the National Science Foundation - United States (CMMI-

418 1000580, 1563551) and the Research Stimulation Program, The University of Alabama are

419 highly appreciated.

420 References

421 [1] WBCSD, (n.d.). http://www.wbcsd.org/publications-and-tools.aspx (accessed February 17, 422 2017).

423 [2] T. Khadiran, M.Z. Hussein, Z. Zainal, R. Rusli, Encapsulation techniques for organic

424

425

426 [3] Y. Zhang, G. Zhou, K. Lin, Q. Zhang, H. Di, Application of latent heat thermal energy

427 storage in buildings: State-of-the-art and outlook, Build. Environ. 42 (2007) 2197-2209.

428 [4] N. Zhu, Z. Ma, S. Wang, Dynamic characteristics and energy performance of buildings 429 using phase change materials: A review, Energy Convers. Manag. 50 (2009) 3169-3181.

430 [5] W. a. Qureshi, N.-K.C. Nair, M.M. Farid, Impact of energy storage in buildings on 431 electricity demand side management, Energy Convers. Manag. 52 (2011) 2110-2120.

432 [6] A. Waqas, Z. Ud Din, Phase change material (PCM) storage for free cooling of buildings - 
A review, Renew. Sustain. Energy Rev. 18 (2013) 607-625.

434 [7] P.C. Tabares-Velasco, C. Christensen, M. Bianchi, C. Booten, Verification and Validation of EnergyPlus Conduction Finite Difference and Phase Change Material Models for Opaque Wall Assemblies, Golden, Colorado, 2012.

[8] K. Biswas, J. Lu, P. Soroushian, S. Shrestha, Combined experimental and numerical evaluation of a prototype nano-PCM enhanced wallboard, Appl. Energy. 131 (2014) 517529.

[9] V. V. Tyagi, S.C. Kaushik, S.K. Tyagi, T. Akiyama, Development of phase change materials based microencapsulated technology for buildings: A review, Renew. Sustain. Energy Rev. 15 (2011) 1373-1391.

[10] R. Russell, S.S. Sunder, P. D. Domich, "Federal Research and Development Agenda for Net-Zero Energy , High-Performance Green Buildings.” Report of the Subcommittee on Buildings Technology Research and Development, 2008. and applications for microencapsulated phase change materials (MPCM): A review, Renew. Sustain. Energy Rev. 53 (2016) 1059-1075.

[12] M. Hunger, A.G. Entrop, I. Mandilaras, H.J.H. Brouwers, M. Founti, The behavior of selfcompacting concrete containing micro-encapsulated Phase Change Materials, Cem. Concr. Compos. 31 (2009) 731-743.

L. Zhao, H. Wang, J. Luo, Y. Liu, G. Song, G. Tang, Fabrication and properties of microencapsulated n-octadecane with $\mathrm{TiO} 2$ shell as thermal energy storage materials, Sol. 
Energy. 127 (2016) 28-35.

455

456

457

458

459

460

461

462

463

464

465

466

467

468

469

470

471

472

473

474

[14] B. Li, T. Liu, L. Hu, Y. Wang, L. Gao, Fabrication and Properties of Microencapsulated Paraffin@SiO 2 Phase Change Composite for Thermal Energy Storage, ACS Sustain. Chem. Eng. 1 (2013) 374-380.

[15] B. Xu, Z. Li, Paraffin/diatomite composite phase change material incorporated cementbased composite for thermal energy storage, Appl. Energy. 105 (2013) 229-237.

[16] B. Xu, Z. Li, Performance of novel thermal energy storage engineered cementitious composites incorporating a paraffin/diatomite composite phase change material, Appl. Energy. 121 (2014) 114-122.

[17] B. Xu, H. Ma, Z. Lu, Z. Li, Paraffin/expanded vermiculite composite phase change material as aggregate for developing lightweight thermal energy storage cement-based composites, Appl. Energy. 160 (2015) 358-367.

[18] M. Kheradmand, J. Castro-Gomes, M. Azenha, P.D. Silva, J.L.B. De Aguiar, S.E. Zoorob, Assessing the feasibility of impregnating phase change materials in lightweight aggregate for development of thermal energy storage systems, Constr. Build. Mater. 89 (2015) 4859.

[19] M. V Pankova, E. V Fomenko, N.N. Anshits, T.A. Vereshchagina, A.G. Anshits, Microspherical Carriers and Adsorbents for the Processes in Corrosive Media, Chem. Sustain. Dev. 18 (2010) 509-516.

[20] P.P. Bartake, D.N. Singh, Determination of Crushing Strength of Cenospheres, J. ASTM Int. 2 (2005) Paper ID JAI13092. 
475 [21] E. V. Fomenko, A.A. Bobko, A.N. Salanov, I.A. Kirilyuk, I.A. Grigor'ev, V. V.

476 Khramtsov, et al., Perforated cenosphere supported $\mathrm{pH}$ sensitive spin probes, Russ. Chem.

$477 \quad$ Bull. 57 (2008) 493-498.

478 [22] Y. Xie, S.D. McAllister, D.B. Edwards, I.F. Cheng, Fabrication of porous hollow glass

479 microspheres, J. Power Sources. 196 (2011) 10727-10730.

480 [23] L. Liston, M. Krafcik, Y. Farnam, B. Tao, K. Erk, J. Weiss., Toward the use of phase

481

482

483

484

[24] D.J. Corr, S.P. Shah, Final report:design and application of high-volume fly ash self485

[26] ASTM, C305-14: Standard Practice for Mechanical Mixing of Hydraulic Cement Pastes and Mortars of Plastic Consistency, West Conshohocken, PA, 2014. consolidating concrete with the incorporation of nanoparticles, 2012.

[25] J.F. Muñoz, R.C. Meininger, J. Youtcheff, New Possibilities and Future Pathways of Nanoporous Thin Film Technology to Improve Concrete Performance, Transp. Res. Rec. J. Transp. Res. Board. 2142 (2010) 34-41.

[27] ASTM, C109/C109M-13: Standard Test Method for Compressive Strength of Hydraulic Cement Mortars ( Using 2-in . or [ 50-mm ] Cube Specimens ), West Conshohocken, PA, 2010.

H. Zhang, X. Wang, Synthesis and properties of microencapsulated n-octadecane with polyurea shells containing different soft segments for heat energy storage and thermal 
regulation, Sol. Energy Mater. Sol. Cells. 93 (2009) 1366-1376. 